\title{
OBESITY AND SYSTEMIC HYPERTENSION IN ACCRA COMMUNITIES
}

\author{
*A.L.O. ESCALONA, MERIAM SARFO AND LUCY KUDUA \\ Diagnostic Department, National Cardiothoracic Centre, Korle Bu Teaching Hospital, Accra.
}

\section{SUMMARY}

The study was carried out to determine the prevalence of obesity associated with systemic hypertension in four communities in Accra. A total of 598 persons, of whom 257 were male and 341 female aged 15 year and above were examined. Their blood pressurc, weight, and height were measured; and from weight and height calculated the body mass index.

The results show that $22.6 \%$ were overweight (BMI $25-29 \mathrm{~kg} / \mathrm{ml}^{2}$ ) and $17.2 \%$ were obese (BMI > $30 \mathrm{~kg} / \mathrm{m}^{2}$ ). Overweight/obesity incrensed with age peaking at age 55-64 years and then falling. Obesity was about twice as common in women than men. The prevalence of hypertension (BP > 140/90 $\mathrm{mmHg}$ ) was $26.8 \%$. There was a positive relationship between body mass and hypertension. In the sludy population the prevalence of hypertension was similar in males and females.

Keywords: Body mass, hypertension.

\section{INTRODUCTION}

The World Health Organisation has declared obesity as a global epidemic'. In Europe more than half of the adult population is overweight or obese, and in the United States, the report suggests that alpproximately one-third of persons 20 years of age and above fall into this catcgory. The prevalence of obesity also has increased in developing countrics.

Obesity may be defined as an excess body fat content. All methods of measuring the fat content in living subjects are indirect. Body Mass Index (the body weight in kilograms divided by the square of the height in metres) is the preferred way of calculating obesity in clinical practice ${ }^{1.2}$.

Obesity occurs when the calories intake exceeds the energy requirements of the body both for physical activity and for growth. The increased prevalence of obesity has been attributed to genetic factors, sedentary lifestyle and readily available palatable, high-fat foods.

Somelimes cultural beliefs equate success with obesity. In groups in which great emphasis is placed on food, there is a tendency to overcat. In some societies fat men are respected and fat women considered beautiful.

Overweight is associated with an increased rate of mortality at all ages. This is primarily due to cardiovascular discase, hypertension, diabetes mellilus, gall bladder disease, and ccrtain forms of cancer, for instance, endometrial cancer and postmenopausal breast cancer in women, prostate cancer in men, and coloreclal cancer in both men and women.

In addition obesity significantly impairs the quality of life. Many obese individuals suffer pain and have restricted mobility because of mechanical disabilitics. They experience low self-esteem, depression, emotional distress and other psychological problems because of social prejudices and discrimination.

On the other hand, the economic costs associated with obesity are substantial. These include both the direct cost of health care, and indirect cost associated with low produclivity, caused by illness and disability.

Our experience in the hospital and the community shows that obesity is common in Ghanaians, and this is associated with other risk factors essential to the genesis of hypertension. Moreover we have noted certain tolcrance and acceptance of obesity that may be attributed to the cultural and social patterns. Thirty years before our study Haddock had noted a high prevalence of obesity in medical

- Author for correspondence 
out patients of the Korle Bu Teaching Hospital $(\mathrm{KBTH})$; the prevalence of obesity was higher in hypertensives than normotentives ${ }^{3}$.

Under the terms of a technical assistance agreement between the Governments of Ghana and Cuba, a Cuban Health Brigade team undertakes clinical assignments in Ghana for periods of 2 years at a time. Each year the team holds a health week where these physicians are located and they pick on a theme for the purpose. During the 2-year duty tour of October 2000 - September 2002, a health week was held with Hypertension as the theme. The objective of this communication is to report on the study to determine the prevalence rates of hypertension and obesity in various communities in Greater Accra Region. Previous community studies had been in the Administrative Centre of Accra (Victoriaborg and Christianburg) and a suburb Mamprobi ${ }^{4.5}$. Our study widened the scope of the spread of the population of Accra.

\section{METHODOLOGY}

\section{The Population}

Six communities, urban and semi urban in Accra, were randomly chosen. There was no census of the population taken but information was relayed to the communities of each locality through an identifiable traditional leader, concerning the impending exercise. Each day the survey field team moved from one location to the other, working between 0900 hours - 1500 hours. The blood pressures were taken by State Registered Nurses who had been trained in blood pressure (BP) measurement using standard methods. These nurses normally take the BP of the $60-80$ patients a day, attending the cardiac and hypertension clinic of the National Cardiothoracic Centre in Accra. They also took the heights and the weights of the subjects.

Hypertension was defined as a BP of more than $140 / 90 \mathrm{mmHg}^{6}$ or a patient on anti-hypertensive therapy.

Overweight was defined as a $\mathrm{BMI}>25 \mathrm{~kg} / \mathrm{m}^{2}$ with sub-classification: Pre Obese BMI $25.0-29.9 \mathrm{~kg} / \mathrm{m}^{2}$ and Obesity BMI $>30.0 \mathrm{mg} / \mathrm{m}^{2}$.

The statistical method used was the z-score for comparing two percentages.

\section{RESULTS}

\section{Distribution of population $x$ Iocation $x$ sex}

- There were 598 persons aged 15 years and above; consisting of 257 males (43\%) and 341 females $(57 \%)$. The communities studied were Teshie 58, 9.7\%; Sakaman 124, 20.7\%; Awoshic 118, 19.7\%;
Oyinase 97, 16.2\%; Dansoman 73, 12.2\% and Mamprobi 128, 21.4\%.

Distribution of categories of body mass index and prevalence of hypertension. Table 1.

The prevalence of hypertension thus increased significantly with body mass from $20.5 \%$ at $\mathrm{BMI}$ $18.5-24.9 \mathrm{~kg} / \mathrm{m}^{2}$ (normal), to $42.7 \%$ at $>30 \mathrm{~kg} / \mathrm{m}^{2}$ (obesity).

Table 1 Distribution of hypertension among categories of body mass index in both sexes

\begin{tabular}{cccc}
\hline $\begin{array}{c}\text { Body mass } \\
\text { index }\end{array}$ & $\begin{array}{c}\text { No. sub- } \\
\text { jects }\end{array}$ & $\begin{array}{c}\text { Percentage } \\
\text { of selected } \\
\text { population } \\
\%\end{array}$ & $\begin{array}{c}\text { Prevalence } \\
\text { of hyper- } \\
\text { tension } \\
\%\end{array}$ \\
\hline $\begin{array}{c}\text { Underweight } \\
<18.5\end{array}$ & 23 & 3.8 & 1.75 \\
$\begin{array}{c}\text { Normal } \\
18.5-24.9\end{array}$ & 337 & 56.4 & 20.5 \\
$\begin{array}{c}\text { Overweight } \\
25-29.9\end{array}$ & 135 & 22.6 & 37.8 \\
$\begin{array}{c}\text { Obesity } \\
\geq 30\end{array}$ & 103 & 17.2 & 42.7 \\
\hline
\end{tabular}

Prevalence of hypertension, overweight and obesity $x$ sex. Table 2

There was not much significant difference between males and females with respect to hypertension in the population, $p>0.5$; Overweight was commoner in females than males but the difference was not statistically significant. Obesity was thrice as common in females than in males, the difference was highly significant, $p<0.001$.

Prevalence of hypertension and overweight was equal in both sexes. However obesity was highly prevalent among females.

Prevalence of overweight and obesity in age groups. Table 3

Overall prevalence of overweight was $22.6 \%$ and of obesity $17.2 \%$.

Thus there is a positive relationship between increasing age and the prevalence of overweight and obesity, though the prevalence of overweight peaked at 45-54 years whilst that of obesity peaked a decade later only to drop again after the age of 64 years. 
Table 2 Prevalence of hypertension, overweight and obesity among males and females

\begin{tabular}{lcccc}
\hline & $\begin{array}{c}\text { Males } \\
\mathbf{N = 2 5 7} \\
\%\end{array}$ & $\begin{array}{c}\text { Fe- } \\
\text { males } \\
\mathbf{N = 3 4 1} \\
\%\end{array}$ & $\begin{array}{c}\text { Total } \\
\mathbf{N = 5 9 8} \\
\%\end{array}$ & P value \\
\hline $\begin{array}{l}\text { Hypertension } \\
>140 / 90 \mathrm{mmHg}\end{array}$ & 27.6 & 26.1 & 26.8 & $<0.5 \mathrm{NS}$ \\
$\begin{array}{l}\text { Overweight } \\
\begin{array}{l}\text { (BMI } 25.0- \\
\left.29.9 \mathrm{~kg} / \mathrm{m}^{2}\right)\end{array}\end{array}$ & 20.2 & 24.3 & 22.6 & $<0.5-0.3>$ \\
$\begin{array}{l}\text { Obesity } \\
\left(\mathrm{BMI}>30 \mathrm{~kg} / \mathrm{m}^{2}\right)\end{array}$ & 7.9 & 24.3 & 17.2 & $<0.001 \mathrm{HS}$ \\
\hline
\end{tabular}

NS=Not significint, IIS=Highly significant

Table 3 Prevalence of overweight and obesity in age groups males and females together

\begin{tabular}{cccc}
\hline Age in years & $\begin{array}{c}\text { Over- } \\
\text { weight } \\
\mathbf{1 3 5} \\
\mathbf{\%}\end{array}$ & $\begin{array}{c}\text { Obesity } \\
\mathbf{1 0 3} \\
\mathbf{\%}\end{array}$ & $\begin{array}{c}\text { Over- } \\
\text { weight/obesity } \\
\mathbf{2 3 8} \\
\mathbf{\%}\end{array}$ \\
\hline & & & \\
$15-34$ & 19.0 & 12.2 & 31.2 \\
$35-44$ & 22.3 & 16.8 & 39.1 \\
$45-54$ & 30.3 & 20.5 & 50.8 \\
$55-64$ & 20.8 & 31.3 & 25.1 \\
$65+$ & 21.4 & 21.4 & 42.8 \\
\hline & & & \\
Total & $\mathbf{2 2 . 6}$ & $\mathbf{1 7 . 2}$ & $\mathbf{3 9 . 8}$
\end{tabular}

\section{DISCUSSION}

The communities were randomly selected without any knowledge as to the behaviour of blood pressure and the prevalence rates of hypertension in those communities. It is conceded, however, that without knowledge of the denominator population, almost certainly, we cannot be.positive about the representativeness of the sample with respect to the study population as a whole.

Obesity as defined was noted in $17.2 \%$ of our study population as compared to $6.2 \%$ by Nube et $\mathrm{al}^{7}$ and $5.7 \%$ and $7.4 \%$ amongst Civil Servants and Mamprobi residents respectively ${ }^{8.2}$. The Ghanaian rates of obesity of $5.7-17.2 \%$ compare with $18.5 \%$ amongst citizens of the United Kingdom and $24.7 \%$ amongst the citizens of the United States of America!.

The finding of the higher prevalence rates of overweight/obesity in females more than males, and the rising prevalence of body mass in both sexes with age are phenomena noted of other societies $^{10,11}$.

\section{Hypertension}

The prevalence of hypertension defined as a BP more than $140 / 90 \mathrm{mmHg}$ was noted in $26.8 \%$ of subjects of the communities. About that same time, a community study of Greater Accra, involving different communities from the current study, by Amoah, noted a rate of $28 \%$ in 4733 subjects ${ }^{12}$. Earlier in 1975, Pobee had found amongst Mamprobi residents a rate of $25 \%$ in his 4703 subjects ${ }^{13}$. The prevalence rate of $26.8 \%$ in our communities compare with $26.6 \%$ noted in Kpando in the Volta Region and $32 \%$ in Zebilla in the Upper East Region ${ }^{14}$. Thus, with the caution indicated at the beginning of this discussion in mind, our study confirms the high prevalence rates of hypertension already noted in the Greater Accra Region. Previous studies reported above were about the Western and Eastern sub districts of Accra and at the very least, we have added other sub districts of Greater Accra Region.

\section{Overweight/obesity and hypertension}

That overweight/obesity is a risk factor for systemic hypertension is well documented in many societies, that we can only echo the saying attributed to Pickering, one of the giants in the field of hypertensionology: "The positive correlation (between body mass and blood pressure) has been so often as to leave room for no doubt"15. Indeed this relationship was first noted of Northern Americans by Terry in $1923^{16}$. Our finding of the positive relationship between body mass and hypertension in the community has confirmed Haddock's ${ }^{3}$ observation of patients attending the Korle $\mathrm{Bu}$ Teaching Hospital.

\section{CONCLUSION}

Our study shows that overweight/obesity is common in Ghana and that it rises with increasing age till the age of 65 years; and that overweight/obesity tended to be more common in females.

There was a high prevalence of hypertension in both sexes. There was a higher prevalence of hypertension in both sexes in the overweight/obesity than the normal weight persons in a ratio of $2: 1$. Thus obesity is a risk factor for hypertension.

\section{REFERENCE}

1. Obesity. Preventing and managing the global epidemic. A report of a Who Consultant on Obesity $3^{\text {rd }}-5^{\text {lt }}$ June 1997. WHO Geneva 1997.

2. WHO Physical Status. The use and interpretation of anthropometry. Report of WHO expert 
committec. Geneva. WHO Technical Report Series 1995: 854: 368-369.

3. Haddock DRW. Obesity in medical outpatients in Accra. Ghana Med J Dec 1969; 251 254.

4. Pobee JOM, Dodu SRA, Larbi EB, Pisa and Strasser $T$. Is hypertension a problen in Ghana? Trop Doc 1979; 89-92.

5. Ikeme AC, Pole D, Pobee JOM, Larbi EB, Blankson JM and Williams $\mathrm{H}$. The Memprobi survey-a screening survey for cardiovascular disease and with factors in Africa. Methodology and validity. WHO Bull 1978; 57: 81-82.

6. National high blood pressure education programme. The sixth report of the Joint National Committee of Prevention, Detection, Evaluation and Treatment of Blood Pressure. Arch IIIt Med 1997; 157; 2413-2146.

7. Nube M, Asenso-Okyere WK, van der Boom GJM. Body mass index as indicator of standard of living in developing countries. East $J$ Clin Nutr 1998; 52: 136-144.

8. Pobec JOM. In sickness and in health. Some aspect of the general and cardiovascular health status of Ghanaian civil servants. Disscrtation for the award of Doctor of Medicine Degree of the University of London 1992.

9. Pobee JOM. The heart of the matter: Community profile of cardiovascular diseases of a sub-Saharan African country: The Ghana paradigm-a report on the Mamprobi (Ghana) cardiovascular health project-unpublished. Continuing Medical Education Programme. Ghana Medical Association 2000 in Accra, Ghana.
10. Rotimi CN, Cooper RS, Osotimehin B et al. Distribution of anthropometric variables and the prevalence of obesity in populations of West Africa origin. The International Collaborative Study on Hypertensive Blacks (ICSHIB) Obesity Research 1995; 3(suppl 2): 95s-105s.

11. McDonough JR, Garrison GE, and Barnes CG. Hypertensive disease among Negros and Whites. A study in Evans County, Georgia. Alln Imt Med 1964; 61: 208-228.

12. Amoah AGB. Hypertension in Ghana: A cross-sectional community prevalence study in urban and rural Greater Accra. A report of the Non Communicable Diseases Survey AD 1998 by the University of Ghana Medical School and the Ministry of Health of Ghana.

13. Pobee JOM. The journey of Africans from Normotensionville to Hypertensionville: The Ghanaian paradigm - A report on the Mamprobi Cardiovascular Health Survey Unpublished. Presented at Annual Scientifuc Meeting of Ghana Chapter of West African College of Physicians 2000.

14. Olivera AL, Pevez JP, Pena LEM, Dominguez MF, Aguilar ADR, Robles AR and Marray SLS. Hypertension in 5 regions in Ghana - An unpublished report of a survey by Cuban Health Brigade 2000-2002.

15. Pickering $\mathrm{G}$ quoted by Tyroler HA, Heyden $\mathrm{S}$, Barnes CG. Wcight and hypertension: Evans county studies in blacks and whites. In: epidemiology and control of hypertension ed 0 Paul. Stratton Intercontinental Medical Publishers New York 1975; 177-201.

16. Terry A.H. Obesity and hypertension. JAMA 1923; 31: 1283-1284. 